\title{
The Revitalization of Nivkh on Sakhalin
}

\section{Gruzdeva, Ekaterina}

Routledge

2018

Gruzdeva , E \& Janhunen , J A 2018 , The Revitalization of Nivkh on Sakhalin . in L Hinton , L Huss \& G R (eds), The Routledge Handbook of Language Revitalization . , 45 , Routledge , Abingdon , pp. 464-472 . https://doi.org/10.4324/9781315561271-58

http://hdl.handle.net/10138/311577

https://doi.org/10.4324/9781315561271-58

acceptedVersion

Downloaded from Helda, University of Helsinki institutional repository.

This is an electronic reprint of the original article.

This reprint may differ from the original in pagination and typographic detail.

Please cite the original version. 


\title{
Revitalization of Nivkh on Sakhalin
}

\author{
Ekaterina Gruzdeva and Juha Janhunen
}

\section{CURRENT SOCIOLINGUISTIC SITUATION}

Nivkh1 is an isolate language of Sakhalin Island and the Amur region of the Russian Federation. The language is traditionally classified as "Paleosiberian" together with a number of other languages of Siberia and the Russian Far East. Nivkh may be divided into five geographically distinct varieties, which may be identified as Amur, West Sakhalin, North Sakhalin, East Sakhalin, and South Sakhalin Nivkh. Amur Nivkh is spoken on the Lower Amur on the continent, while the other varieties are spoken on Sakhalin. South Sakhalin Nivkh was spoken on southern Sakhalin, which was under Japanese administration from 1905 till 1945. After the war, the speakers were evacuated to Japan, where the language has now become extinct. North Sakhalin Nivkh was spoken on the Schmidt Peninsula on northernmost Sakhalin, but in the 1950s its speakers were resettled with those of West Sakhalin Nivkh, leaving only a few fluent North Sakhalin Nivkh speakers today. East Sakhalin Nivkh, also known as Nighvng, is spoken in eastern and central Sakhalin.

Sakhalin is separated from the continent by the narrow Tatar Straight. The Nivkh on both sides of the straight have always had close contacts with each other, and the West Sakhalin variety is in many respects close to Amur Nivkh on the continent. Even so, the ethnic and linguistic status of the Nivkh speakers on Sakhalin is somewhat different from those on the continent. The present paper is only concerned with the situation on Sakhalin, which today belongs, together with the Kuril Islands, to the administrative entity of Sakhalin Oblast, with the capital in Yuzhno-Sakhalinsk. The two main varieties of Nivkh on Sakhalin today are West Sakhalin Nivkh and East Sakhalin Nivkh, with North Sakhalin Nivkh also surviving marginally. Sakhalin is the largest island of Russia, with a modern population of about half a million people. The Nivkh constitute the most ancient and most numerous group of the Indigenous peoples currently present on the island.

Traditionally, the Nivkh were fishermen and sea-mammal hunters who lived in small settlements along the seashores and rivers in the northern part of Sakhalin. Being semi-sedentary, the Nivkh migrated regularly between winter and summer camps. Other Indigenous groups on Sakhalin are the reindeer-breeding Uilta (Orok) and Ewenki in the middle part of the island, as well as, historically, the Sakhalin Ainu in the south. Since the second half of the 19th century, as a result of Japanese and Russian colonization, the traditional economic and cultural landscape of Sakhalin has been gradually changing. Economic development and industrial exploitation of the island, followed by massive immigration of non-indigenous population, as well as the political, socioeconomic and cultural impact of the colonizers, has dramatically affected the habitat of the indigenous peoples, leading to the decline of the traditional occupations, cultures and languages (Gruzdeva 2015;2016).

The size of the ethnic Nivkh population has remained relatively stable during the known history of Sakhalin and has only insignificantly changed after the inclusion of the island into the Russian realm in 1875 . There are currently about 4,700 Nivkh in Russia, of whom close to 3,000 live on Sakhalin. On the other hand, during the last hundred years the number of the Nivkh speakers has dramatically decreased and 
currently comprises less than 200 persons, half of whom live on Sakhalin. The proportion of Nivkh speakers within the total population is very low, comprising about $5 \%$ on Sakhalin, as opposed to almost $100 \%$ in the early 20 th century. There are no significant differences in this respect between the Nivkh spoken on the continent and on Sakhalin. Proficiency in Nivkh involves a continuum that ranges from fully or almost fully competent speakers of the oldest generation down to semi-proficient speakers and rememberers of the younger generations.

The transmission of the Nivkh language from parents to children was interrupted several decades ago as a result of demographic, economic and political changes, including, perhaps most importantly, the relocation of the Nivkh population to a small number of large settlements with a Russian-dominated mixed population, accompanied by the introduction of a system of boarding schools functioning only in the Russian language. At the moment, all ethnic Nivkh have almost completely switched to using the Russian language for all practical purposes, including communication between family members. Even those elderly speakers who are still competent in Nivkh prefer to use Russian in everyday contexts. Nivkh has lost almost all of its functions; it is used only during ceremonies and festivals, as well as, very rarely, as a special means of communication between a few fluent Nivkh speakers. In the UNESCO Atlas of Endangered Languages, Nivkh is listed as a moribund language in imminent danger of disappearing.

\section{TRADITIONAL METHODS OF LANGUAGE MAINTENANCE}

The work on the maintenance of the Nivkh language has been developing along the following three lines: (i) language documentation, (ii) school teaching, (iii) language courses.

\subsection{Documentation of Nivkh}

The documentation of Nivkh began in the late 19th century, with the work of two political exiles, Bronisław Piłsudski (1866-1918) and Lev Shternberg (1861-1927), and was continued during the following hundred years by Russian, European, Japanese and American scholars. Unfortunately, a considerable part of the collected materials, including samples of folklore and mythological texts, is stored in personal and academic archives and remains unpublished.

In recent years, documentation has also been conducted by activists working in the Sakhalin Regional museum, located in Yuzhno-Sakhalinsk, as well as in the Center for Development and Preserving of Traditional Cultures of Indigenous Peoples of the North Kykhkykh ("Swan"), located in Nekrasovka. One of the long-term successful projects led by Kykhkykh is the publication of a monthly Nivkh-Russian newspaper Nivkh Dif ("Nivkh Word"). The newspaper has been published since 1990, has a circulation of 250 copies, and is highly valued by the community. It contains articles mainly in the West Sakhalin dialect, but there are also occasional contributions in the North Sakhalin and East Sakhalin dialects. The newspaper performs not only an informative, but also a symbolic role, demonstrating that the Nivkh language is not yet dormant and may function in various domains, including, in particular, media.

Another example of positive involvement in the maintenance of Nivkh cultural and linguistic heritage is the activity of the Nogliki regional library. Since 2006, it has been publishing colourful booklets of Nivkh tales and stories recorded from local speakers and illustrated by Nivkh children. Several books from the collection include 
CDs with audio recordings. It also has to be mentioned that Vladimir Sangi (born 1935), a professional author of considerable international renown and a native speaker of East Sakhalin Nivkh, is a resident of Nogliki. Sangi publishes regularly literary works, including translations, in his native dialect.

The local work done on the documentation of Nivkh is very important especially for the preservation of the language in its written and literary forms. The published books can potentially also be used for teaching Nivkh in various contexts. However, in spite of their colourful appearance, these editions cannot solve the problem of maintaining the oral language, which at the moment represents the biggest challenge in the field of Nivkh language preservation.

\subsection{Teaching of Nivkh at school and in the kindergarten}

Nivkh has a rather long history of being used in school. The first Roman-based Nivkh alphabet for the Amur variety, on the basis of which the first school books and newspapers were produced, was created as early as 1931. The Sakhalin varieties of Nivkh remained without orthography. The main problem faced by the educators at that time were connected with the fact that native children had to cope with learning to read and write two languages in two different scripts, Nivkh in the Roman alphabet and Russian in the Cyrillic script. For that reason, but also because of the political and cultural dominance of Russian, it was decided to create a new Cyrillic alphabet for Nivkh. Such an alphabet was created by Erukhim Kreinovich (1906-1985) as early as 1937, but it remained completely unused, since soon the whole school curriculum switched to using only Russian.

In 1979, two new alphabets, one for the Amur and West Sakhalin dialects, and the other for the East Sakhalin dialect, were adopted, and soon afterwards two new textbooks were published. Another series of textbooks appeared in 2008 after the adoption of a new school programme. In 2009-2013 the first multimedia textbooks and several school supplies for the Amur dialect were issued. A practical dictionary prepared by Chuner Taksami (1931-2014), a native Nivkh scholar, was first published in 1983. Even so, there is an obvious lack of contemporary learning materials, especially multimedia ones. At the moment, written Nivkh exists predominantly as a language of myths and tales, with no connection to modern life. The potential offered by the two Nivkh literary languages remains unused for practical purposes. An additional reason for this is that the official alphabets used for writing Nivkh contain many special letters and diacritic symbols, absent in the regular Cyrillic script. There is an obvious need to create an alternative orthography that would be easier to use in the context of modern digital technology (Gruzdeva and Janhunen 2016).

Soon after the introduction of the new official alphabets and literary languages, the systematic teaching of the Nivkh language started in two Nivkh schools and three kindergartens in 1981-1982. This activity continues up to the present day, though the proportion of participating children has varied in the course of time. In Nekrasovka, the teaching takes place in the West Sakhalin dialect, while in Nogliki and Chir-Unvd the East Sakhalin dialect is used. Currently the language is included in the school curriculum only as an elective subject and with only one weekly hour of teaching. Such a very small amount would possibly be sufficient if the children knew the language and used it at home, but in a situation in which the native language classes at school are the only environment where the language can be heard it is difficult to expect any visible results. Kindergartens do not improve the situation, for the language is used in them only for symbolic functions, such as greetings and 
occasional songs and plays.

After graduating from school, the young people have the option of continuing to study Nivkh traditional culture and language in the Technological College of Handicrafts of the Peoples of the North in Poronaisk. The Nivkh language has, however, a very minor role in the curriculum. At the post-graduate level, the Institute of the Peoples of the North (formerly the Northern Faculty) of the Herzen State Pedagogical University in St. Petersburg is the only higher education institution in Russia that has a programme for training specialists in Nivkh language, culture and pedagogy. This is the principal place where Nivkh school teachers are prepared, but the problem is that many of those who arrive in St. Petersburg turn out to be unwilling to return to their villages to take up the teacher's call.

The central problem encountered in school teaching is that all Nivkh schoolchildren today speak Russian as their first and only language. Although Nivkh is for them a "foreign" language and should be taught as such, the school programme continues to be oriented towards native speakers. The actual work in the classes focuses on basic lexicon and elementary reading skills. After the school course, the children can at most read the texts in the primers, but they are unable to understand any other texts, nor do they have any speaking skills. Another problem is that the teachers themselves do not have full competence in Nivkh. Most teachers responsible for the native language classes for Nivkh children know the language only passively and use it only in the school context. They often experience difficulties in conversing with fully competent speakers, and in many cases feel ashamed of their insufficient command of Nivkh. At the same time, teachers usually do not get any notable help from the competent speakers.

Nevertheless, the general attitude to the teaching of Nivkh remains positive, and many community members see the school as a primary source of learning, or, more precisely, of getting acquainted with, the Nivkh language. The teaching of Nivkh also performs a symbolic function, supporting ethnic identity and proving that something is being done to maintain the language.

\subsection{Nivkh language courses}

During the last decades, local activists have been periodically trying to organize Nivkh language courses for adults in some Nivkh settlements. For instance, for many years, Nivkh women in Nogliki have been active in the Nivkhinka club, where the language is also studied. However, the meetings take place irregularly and the activities are oriented towards the written, not the oral, language. There is a constant lack of teachers and teaching materials, and with the passing away of the oldest fluent speakers, the Russian language sounds at the meetings more often than Nivkh. There are a few community leaders who have a strong knowledge of Nivkh and who support the preservation of the language, but they are not familiar with the methods of language revitalization. Also, the difficult socioeconomic and ecological situation on Sakhalin turns the thoughts of the indigenous population first of all on physical survival, not on language maintenance. Informal community activities that would create a domain for language use are therefore rare and irregular.

\section{REVITALIZATION PROJECT}

\subsection{Prerequisites and beginning of the project}


The idea to start a project on the revitalization of Nivkh on Sakhalin was born after the ethnolinguistic expedition of Finnish researchers and students to Sakhalin in the summer of 2014. The results of the sociolinguistic surveys carried out by the members of the expedition demonstrate that the local Nivkh communities are very concerned about the future of their ethnic language. They understand very well the important role language plays in preserving their ethnic and cultural heritage, and they are also willing to collaborate with professional linguists in order to ensure language survival. The survey also revealed that each of the extant Nivkh local communities still has at least a few highly proficient speakers, several more semi-proficient speakers and even more non-speakers who are committed to learn the native (ethnic) language.

The project that emerged from this interaction with the Nivkh communities is based on the Finnish theoretical and practical experience of language revitalization activities that have been carried out among the Saami in Finland (Pasanen 2015), as well as among several Uralic-speaking groups in Russia. The project team consists of specialists on the Nivkh language, experts on language endangerment and revitalization, as well as local language activists. The main goal of the project is to reestablish the Nivkh language, which has ceased being the language of regular daily communication, and bring it back into active use in the Nivkh speech communities. The project aims at "creating" and "re-creating" Nivkh speakers in different age groups by using various well-known revitalization methods.

The project started with a methodological seminar, organized in June 2015 in the settlement of Nekrasovka. About 30 seminar participants represented Nivkh communities from various geographical locations. The implementation of the project was monitored in January 2016 and again in June 2016 in Nekrasovka, Okha, Nogliki, Chir-Unvd, Poronaisk and Yuzhno-Sakhalinsk. In all of these locations, the project team organized various events that targeted both children and adults and were aimed at attracting general attention to the Nivkh language.

\section{2. "Family nests"}

Many Nivkh individuals of the older generation still have a fairly good command of the language, but they do not have and do not look for opportunities to use it. One of the first tasks of the project is to create a suitable psychological environment in order to activate the knowledge of Nivkh and to stimulate its use. This can be achieved by encouraging the use of the language during informal meetings and everyday activities of the speakers, as well as by involving members of the older generation into the informal teaching of the language to the younger generation.

The middle generation of Nivkh, with few exceptions, has only a passive knowledge of the language or does not know it at all. Although many community members of this age groups are actually interested in learning Nivkh as a second language and becoming active speakers, the absence of teachers and teaching materials makes it virtually impossible to organize language courses of the traditional type. In this situation, the project team decided to organize language teaching according to the Master-Apprentice Language Learning Method, which involves the learning of a target language from elderly fluent speakers (= Masters) by adult language learners (= Apprentices) (Hinton 2002). The process of learning takes place in a natural environment on a par with normal everyday activities. The final goal is to activate the passive knowledge of the Nivkh language among semi-speakers of the middle generation and to prepare potential teachers/nurses for Nivkh kindergartens. Within a relatively short period the Apprentices should acquire enough conversational proficiency 
to be able to talk to children in Nivkh.

As it turned out in the course of monitoring, the local participants of the project in Nogliki, Nekrasovka and Chir-Unvd understood the Master-Apprentice method in a somewhat innovative way. Instead of Master-Apprentice pairs, they organized languagelearning teams or "family nests", centered around a Master or two Masters (typically great-grandmothers) and involving representatives of several generations, mostly belonging to the same family. Each "family nest" comes or intends to come together at least once a week and studies the Nivkh language in the form of a game or a play. The groups discuss various topics, such as shopping, cooking, visiting a doctor, etc., and create their own learning materials. Some "family nests" are very active and obviously enjoy their learning activities, which gives hope that this method will indeed bring the expected results, so that committed and motivated semi-speakers and even non-speakers will achieve a communicative competence and become able to use Nivkh for different purposes in various practical situations.

\subsection{Immersion programmes for children}

The issue of developing full-immersion programmes for the Nivkh has never been raised officially, and until the present project the local communities were not aware of the potential benefits of these methods. The main goal of this part of the project is to "create" new speakers in the youngest generation, i.e., in the age group 3-7, by the "language nest" method, which represents a particular type of total-immersion instruction (Grenoble and Whaley 2006: 51-55). Nivkh still has qualified speakers that can be used in a kindergarten setting in combination with trained teachers who are not full speakers. The elders may potentially serve as classroom assistants, until the professional teachers acquire a sufficient competence to use Nivkh. This method has to be used in the current project also for the formal reason that the elders with a full command of the language, but with no formal education, are not permitted to serve as kindergarten teachers in Russia. They can, however, serve as classroom assistants in the presence of professional teachers.

The long-term goals are to build a progressive system by following the lead class and by developing the programme as they move through it. This means that the children in the class will gradually increase their knowledge of the language during the entire kindergarten period. After kindergarten, these children will serve as an input into the regular school system, where the language is being taught as a second language. The children prepared in this way will be able to benefit from the native language classes at school much more than is the case today.

Unfortunately, despite the efforts of the project team, this part of the project has not yet been implemented, as kindergartens administrators are not yet willing to organize immersion groups. They refer to the lack of staff that would be able to teach such groups, the lack of funding to pay the assistants, and the possible lack of interest from parents. The whole idea of Nivkh-Russian functional bilingualism is new and still difficult to accept. In this situation, the project team can only continue working on this issue in collaboration with administrators and parents. Without a doubt, there will have to be more information directed at the parents of school-age children. One possibility that has been discussed is to organize Nivkh immersion language camps in which all generations, including children, parents and grandparents, and even great-grandparents, would be present. Such camps could be organized in several non-urban locations, especially Chir-Unvd and Nekrasovka, but also Nogliki. The idea would be to create a temporary environment for speaking Nivkh. 


\section{PERSPECTIVES AND CHALLENGES}

Apart from the general factors mentioned above, the project on the revitalization of Nivkh encounters three specific challenges, connected with (i) language variation, (ii) language isolationism, and (ii) geographical diversity.

\subsection{Language variation}

In spite of the existence of two literary languages, Nivkh is not standardized at the oral level and is used in several local and individual varieties, some of which differ essentially from each other. Since the speakers of Nivkh have come to their current places of residence from different locations, they may speak various dialects and subdialects even within a single locality. The speakers are typically quite sensitive to dialectal variation and disagree with other speakers about the "correctness" of one or another variety. This, in turn, leads to reluctance to communicate with speakers of the "wrong" variety of Nivkh. Historically, such intolerance seems to be a rather recent phenomenon, and it was apparently caused by the forced relocation and amalgamation of people with different linguistic backgrounds. Earlier, the language in each given locality was apparently more uniform, and the differences that existed between communities were accepted in their geographical context.

It is obvious that in the current situation it is impossible to create a unified standard for the Nivkh language that would satisfy everyone. Instead of normalizing and standardizing, the revitalization project aims at smoothing out the contradictions between the speakers, convincing them to agree with a very broad language norm and accept all the extant variation within the language. The Masters are encouraged to teach the Apprentices in their own dialect or subdialect, as was also historically the case, when a big family formed a separate settlement and spoke a certain variety of the language. In this sense, the newly organised "family nests" actually reproduce the traditional model of language usage and transmission.

Another serious problem is the critical attitude of fluent speakers with regard to those semi-speakers and learners who know Nivkh only insufficiently or poorly. This can easily lead to a situation in which non-fluent speakers no longer dare to practice the language in the presence of fluent speakers. With the beginning of the present project the situation has, however, started to improve. First of all, the older generation has finally realized that in order to ensure the maintenance of Nivkh, all possible forms and levels of language competence should be admitted, recognized and encouraged. Furthermore, the Masters now feel responsible for the progress of their Apprentices and have started to appreciate the desire of the latter to learn the language.

\subsection{Language isolationism}

During the pre-colonial period, the indigenous population of Sakhalin was typically multilingual. Nivkh speakers used to know the languages of neighbouring peoples, and vice versa. In this situation, languages were less tightly connected with ethnicity and more connected with locality than they are today. The present project attempts to recreate this understanding concerning the local nature of languages. The revitalized Nivkh language should be open as a local language of the Nivkh settlements for anyone living in these settlements irrespective of his or her ethnic background. In practice, this means that the Masters should "adopt" not only ethnic Nivkh, but also non-Nivkh, 
including Russian, members into their "family nests". Also, if and when immersion groups of children are established in the Nivkh language, they should be open to any children irrespective of ethnic background.

The idea of non-ethnic local languages is still new to the Nivkh, as well as to the non-Nivkh administrators of the Sakhalin school system. Therefore, the Nivkh language classes are also traditionally offered only to those children who are officially registered as ethnic Nivkh, while local Russian children are not encouraged to learn Nivkh. In order to overcome the marginalization of the Nivkh language, this situation has to be changed, for which reason the project team is actively spreading information concerning the beneficial effects of local functional bilingualism.

\subsection{Geographical diversity}

All settlements involved in the project are different in their demographic and linguistic profiles, which means that the project should be developed differently in different locations. The greatest potential for language revitalization is offered by Chir-Unvd, which is a small and compact village inhabited mostly by ethnic Nivkh. It has a handful of fluent speakers, currently working as Masters in "family nests", as well as a kindergarten and a school, where it is potentially possible to create language immersion groups. Chir-Unvd would also have the potential of becoming an "ethnic village" that could strengthen its profile as a centre of Nivkh traditional culture and ultimately attract visitors in the context of controlled ethnic tourism.

The settlements of Nogliki and Nekrasovka are different in size but similar in many other respects. Each of them has a relatively strong Nivkh community which is actively involved in the language revitalization project. There are kindergartens and schools suitable for immersion programmes. The main challenges are connected with the presence of a large Russian-speaking majority population. In these localities it would therefore be particularly important to advertise Nivkh as a local language and attract also ethnic Russians and other non-Nivkh adults and children to "family nests", immersion groups and school language classes. Both Nogliki and Nekrasovka are also suitable places for organizing summer immersion camps.

Okha, Poronaisk and Yuzhno-Sakhalinsk are all urban environments, in which Nivkh is present only in diaspora. All of these localities have museums in which Nivkh culture and history, together with that of the other indigenous groups of Sakhalin, is presented for the general public. They have also attracted many Nivkh individuals, especially intellectuals. These "City Nivkh" are actively arranging cultural events, but can also be mobilized to arrange language courses and "family nests". It is well known from other parts of the world that language revitalization projects require the support of intellectuals, both those who represent the ethnic group whose language is being revitalized, and others who are willing to learn the language on a local basis. For many reasons, this is particularly possible in Yuzhno-Sakhalinsk, which, incidentally, has also the youngest Nivkh language-learning group of all currently active on Sakhalin.

\section{Conclusion}

As this paper has shown, the traditional methods of revitalization, such as language documentation and language teaching at school, have not brought any substantial results for the preservation of the Nivkh language. Obviously, work on Nivkh language revitalization should now urgently be focused on recreating the natural environment for language use, on establishing and developing language immersion 
programmes for both children and adults, and on creating up-to-date teaching materials for various groups of potential language learners. The outcome of such practical measures will also depend on the willingness of the last speakers to overcome language purism and isolationism, as well as on the perseverance of the new learners to keep up motivation during the long process of language acquisition. Ultimately, the successful revitalization of the Nivkh language will require the combined efforts of both urban and rural communities, both Nivkh and non-Nivkh individuals, and both laymen and professional linguists.

\section{References}

Gruzdeva, Ekaterina (2015). Explaining language loss. The Sakhalin Nivkh case. In H. F. Marten, M. Riessler, J. Saarikivi and R. Toivanen (eds.). Cultural and Linguistic Minorities in the Russian Federation and the European Union. Comparative Studies on Equality and Diversity. Berlin: Springer, 233-252 [Multilingual Education 13].

Gruzdeva, E. 2016. Treasure Island at the turn of the millennium: Socioeconomic and sociolinguistic situation on Sakhalin // Laihonen, P., Sloboda, M. and Zabrodskaja, A. (eds.), Sociolinguistic transitions in former Soviet and Eastern Bloc countries: Recent developments two decades after the regime changed. Peter Lang, 1. (Prague Papers on Language, Society and Interaction / Prager Arbeiten zur Sprache, Gesellschaft und Interaktion; no. 4)

Gruzdeva, Ekaterina and Juha Janhunen (2016). Bringing the orthography of an indigenous language to the digital age: The case of Nivkh in the Russian Far East. Tangut and Other Asian Scripts: Proceedings of the SCRIPTA 2016: 95114. Seoul: Hunmin Jeongeum Society.

Grenoble, Lenore A. and Lindsay J. Whaley (2006). Saving Languages: An Introduction to Language Revitalization. New York: Cambridge University Press.

Hinton Hinton, L. (2002). How to keep your language alive: a commonsense approach to one-on-one language learning. Berkley: Heyday Books.

Pasanen, A. 2015. Kuávsui já peeivičuovâ. 'Sarastus ja päivänvalo'. Inarinsaamen kielen revitalisaatio. Uralica Helsingiensia 9. 